\title{
Collision tumour; Papillary thyroid cancer colliding with squamous oesophageal cancer
}

\author{
${ }^{1}$ Milhan A.B.M., ${ }^{2}$ Sheriff A.M.M., ${ }^{3}$ Jayawikrama M.M.A. \\ ${ }^{1}$ Senior registrar in ENT, ${ }^{2}$ Consultant ENT Surgeon, ${ }^{3}$ Consultant Histopathologist \\ North Colombo Teaching Hospital, Ragama.
}

\section{INTRODUCTION}

Collision tumor is a tumour mass that contains more than one histologically distinct independent malignancies. Collision tumour in the thyroid have been reported involving papillary and medullary carcinoma or papillary and follicular carcinoma or papillary and primary squamous carcinoma. We report a patient with papillary thyroid carcinoma colliding with squamous cell oesophageal carcinoma in the neck.

\author{
Correspondence to \\ Dr.A.M.M. Sheriff \\ Consultant ENT Surgeon \\ North Colombo Teaching \\ Hospital, Ragama. \\ milhan_2004@yahoo.com
}

\section{CASE REPORT}

A 7 I years old lady presented with a rapidly enlarging left neck mass, dysphagia and dysphonia for four months duration. She had a hard thyroid lump with left sided level two neck lymphadenopathy. Indirect Laryngoscopy revealed left vocal cord palsy. Fibreoptic endoscopy revealed narrowing of the oesophageal lumen due to multiple nodules at $18 \mathrm{~cm}$. Fine needle aspiration cytology of thyroid and the neck nodes showed a papillary carcinoma. Total thyroidectomy and left sided cervical block dissection was done. Thyroid tumour was contiguous with the oesophageal wall so complete excision was not possible. Histology showed papillary carcinoma from the thyroid specimen and squamous cell carcinoma from the esophageal wall. She was referred to the consultant oncologist for further management.

\section{DISCUSSION}

The term "collision tumor" refers to coexistent but independent tumors that are histologically distinct. Collision tumors can occur within the same organ or adjacent organs or in conjunction with a systemic malignancy as a metastatic phenomenon'. Various mechanisms have been proposed for collision tumors. "Chance accidental meeting" of two primary tumors is a possibility. Presence of the first tumor altering the microenvironment for cancerous growth of the second primary tumor is another possibility. In our case we do not know which one was the first. The third theory suggests a common stem cell of origin for the two tumours'. A common carcinogenic agent such as radiation to the particular region is another proposed mechanism.
Incidence of collision tumours in the thyroid gland is very low ${ }^{2}$. Papillary thyroid carcinoma can be multicentric, meaning the same papillary growth occurs in multiple sites within the gland is not rare, occurring in a range of $18 \%$ to $22 \%$ of thyroid neoplasms ${ }^{2}$.

Primary squamous cancers of the thyroid gland are very aggressive tumors and typically present with a high incidence of pressure symptoms such as dysphagia and dyspnea ${ }^{4}$. They are extremely rare and account for less than $1 \%$ of all thyroid neoplasms ${ }^{5}$.

The origin of squamous cells within the thyroid gland has many theories. These can be found as a result of persistence of thyroglossal duct or from a branchial pouch.They may also arise from a squamous metaplasia in a papillary carcinoma, anaplastic carcinoma, Hashimoto's thyroiditis or other conditions ${ }^{3,4}$.

The de novo occurrence of primary squamous cancer from follicular cells has also been advocated.

Squamous cell carcinomas are the commonest metastatic disease in the head and neck. Hence, it is important to rule out infiltration of the thyroid gland from an adjacent organ [larynx, tongue base or esophagus ${ }^{6}$, and metastasis from a distant organ before labeling a squamous cell carcinoma as a primary thyroid cancer.Therefore thorough head and neck examination and panendoscopy are mandatory in the work up of squamous cell collision tumours. In our case, the squamous cancer was found in the oesophagus. There was no histological evidence of squamous metaplasia or transformation from one tumour to the other.The histological features of both tumours were distinct and remained consistent. 
Metastasis to the thyroid gland is not uncommon. Liposarcoma, and pulmonary and prostate adenocarcinoma are reported in thyroid collision tumours ${ }^{7}$.

The incidence of thyroid gland involvement in autopsy studies ranges from $1.25 \%-24.2 \%$. The primary tumor can usually be identified in $95 \%$ of the cases. The presence of metastasis to thyroid indicates a disseminated disease and reflects a very poor prognosis, with two months survival from diagnosis to death. However, a previous history of a malignancy is essential to make this diagnosis ${ }^{8}$.

\section{CONCLUSION}

Collision tumors in the thyroid gland are rare but have to be kept in mind when dealing with thyroid tumours especially when the clinical picture is not compatible with the fine needle aspiration cytology findings. In this case, the fast growing nature of the tumor, larger size, nodal metastasis, dysphagia and hoarseness suggested a predominance of the squamous cell carcinoma than a papillary thyroid cancer.

The reporting of similar cases with longer follow up will shed more light on the behavior of collision tumours. A short follow up is a limitation of this report.

\section{REFERENCES}

I. Brandwein-Gensier M, Urken M, Wang B: Collision tumor of the thyroid: a case report of metastatic liposarcoma plus papillary thyroid carcinoma. Head \& Neck 2004, 26:637-64I.

2. Baloch ZW, Mandel S, LiVolsi VA: Combined tall cell carcinoma and Hurthle cell carcinoma (collision tumor) of the thyroid. Arch Pathol Lab Med 200I, I25:54I-543.

3. Sutak J, Armstrong JS, Rusby JE: Squamous cell carcinoma arising in a tall cellpapillary carcinoma of the thyroid gland. J Clin Pathol 2005, 58:662664.

4. Sarda AK, Bal S, Arunabh, Singh MK, Kapur MM: Squamous cell carcinoma of the thyroid. J Surg Oncol 1988, 39:175-178.

5. MeirWarman, Noga Lipschitz, Sergey Ikher: Collision tumour of the thyroid gland: primary squamous cell and papillary thyroid carcinoma. ISRN Otolaryngology 201 I, 10.5402.

6. Nakhjavani MK, Gharib H, Goellner JR, Van Heerden JA: Direct extension of malignant lesions to the thyroid gland from adjacent organ. Endocr Pract 1999, 5:69-7I.

7. John Young, Lindsay Potdevin, Tomer Davidov: Prostate adenocarcinoma metastasis and papillary thyroid carcinoma: a case report of co existing thyroid tumours. Journal of current surgery $2012,4-5 ;|4|-\mid 43$

8. Nakhjavani MK, Gharib H, Goellner JR, Van Heerden JA: Metastasis to the thyroid gland. Cancer 1997, 79:574-578. 